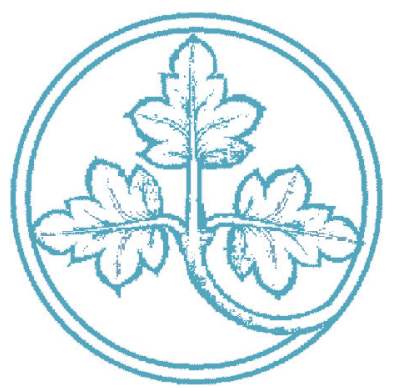

Mitigating the shadow of conflict - The role of social and human capital for the reduction of conflicts

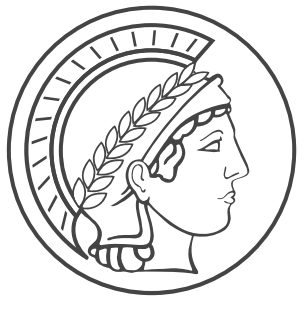


Preprints of the

Max Planck Institute for

Research on Collective Goods

Bonn 2007/5

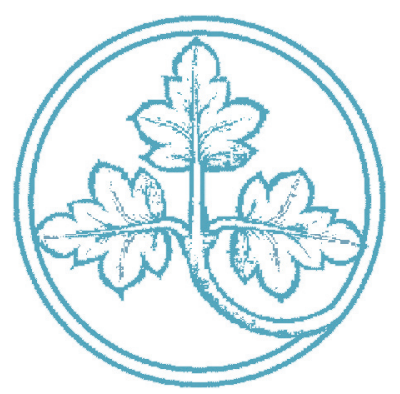

Mitigating the shadow of conflict - The role of social and human capital for the reduction of conflicts

Dorothee Schmidt

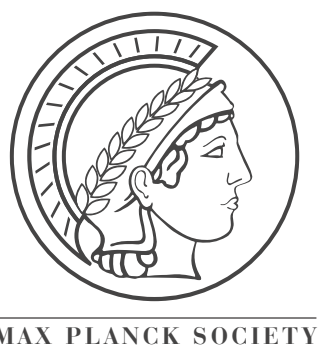




\section{Mitigating the shadow of conflict - The role of social and human capital for the reduction of conflicts}

Dorothee Schmidt

March 2007 


\title{
Mitigating the shadow of conflict - The role of social and human capital for the reduction of conflicts
}

March 22, 2007

\begin{abstract}
One possible solution to mitigate the negative influences of conflict which has been proposed in the literature is to subject the relevant parties to education. Education can take two forms: increasing an individual's human capital on the one hand, increasing her social capital on the other hand. Using a stylized model of a two-individual economy, we derive that increasing an individual's social capital will lead her to reduce her conflict effort, whereas increasing her human capital can induce her to increase her conflict effort. We then analyze which conditions need to be present to induce the individuals to invest into their social capital.

Keywords: Contests, conflict reduction, education, human capital, social capital, morality.

JEL classification: D72, D74, I28, K42, Z13
\end{abstract}




\section{Introduction}

Conflicts are everywhere. They permeate every conceivable layer of social life and reach from social dilemmas, crime, corruption, legal disputes and political lobbying for rents to distributive struggles and out-right war. Among other issues, conflicts constitute a problem as through rent-dissipation they lead to a waste of society's resources which could have been used for different, more productive purposes. While one strand of the literature addressing the problems caused through conflicts has questioned and analyzed the problems due to rent-dissipation (see e.g. Tullock (1980); Hillman and Samet (1987); Hillman and Riley (1989); Leininger (1993); Leininger and Yang (1994); Baye et al. (1994, 1999) for a detailed discussion of the issue), others have chosen to discuss the negative philosophical aspects conflicts involve (see e.g. Hillman (2003)). Even when leaving those aside, given that conflicts entail negative economic consequences and constitute a problem, the question arises of how to limit the shadow of conflict.

While some contributions to the debate focus on the institutional design with which lobbying contests for policy proposals can be reduced (e.g. Epstein and Nitzan (2004); Münster (2005)) other approaches have been suggested. One suggestion to solve the problems arising from conflicts has been to resort to education. Haveman and Wolfe (1984) examine the non-market effects of schooling and identify crime reduction as one of them. Erlich (1975) examines the relationship between education and crime and concludes that those with lower schooling levels have a greater propensity to engage in crimes against property. Still, education can take different forms and it is by no means clear which of these is best suited to deal with the problems posed by conflicts.

On the one hand, education can increase the human capital of a society's members, making them more productive. Grossman and Kim (2004) have raised the argument that education in the form of investment into human capital could deter people from conflict. They argue that by increasing human capital which leads to increased productivity this increases the opportunity costs of conflict of the individuals involved. As a consequence, they will reduce their conflict effort. One the other hand, education is a means to perpetuate the values of society and enculturate its people. It promotes not only values of hard work and of honesty, but as well those that regulate conflict behavior (Usher (1997); Guttman et al. (1992)). For example, the norms "thou shalt not steal" and "thou shalt not kill" which are given in the ten commandments are directly targeted at suppressing harmful and destructive actions.

Norms such as these do not evolve on their own account. Often enough they are shaped by the underlying economic structure of a society and are embedded in the individuals via education. In most societies one can observe major investments into the morality and social values of its members. Schools, churches, other institutions and individuals spend a considerable fraction of their resources to instill and sustain a common morality which regulates the social interactions of a society's members. Coleman has argued that norms which regulate the relationships among people constitute a powerful yet sometimes fragile form of social 
capital (Coleman, 1988). While human capital is embodied in each individual, social capital manifests itself in the relation between individuals. Effective norms which inhibit crime and opportunistic behavior lead to trust between the individuals. This often enough enables them to overcome problems of social dilemmas or public goods provision. Social capital, therefore, while facilitating certain actions which lead to increased productivity of the individuals, constrains (among others) those criminal activities with negative economic impacts. Therefore, they provide positive incentives for production. In the past years, many studies documented the effects of social capital on economic well-being and growth (e.g. (Putnam, 2000; Bjornskov, 2004, 2005; Svendsen and Svendsen, 2004). While a certain positive influence on these variables has by now been well established Putnam (2000) documented in an extensive survey the ongoing decline in the stock of social capital in the United States.

This erosion in social capital might constitute an economic problem and lead to an increase of conflict behavior. In current debates which address the problem of the erosion of common norms - that is the erosion of social capital - the issue has been raised whether public schooling should step in to fill the gap in this second type of education. Without any current consensus on the topic the issue is still subject to a major public debate. This could, for example, be seen in the public discourse caused by the introduction of the subject "Lebenskunde-Ethik-Religionskunde" (life skills-ethics-religion) into the teaching curriculum of schools in the German county of Brandenburg which started with the school year of $2006 / 2007$. At the core of these debates lies the issue of whether public education should concentrate on the task of increasing human capital or whether it should tackle the job of promoting common values of a society as well - that is - to increase its social capital. While these debates for now have stayed largely at a philosophical level, the theoretical issue has to be raised, whether and in which form social and human capital have effect on crime and conflict behavior. Shedding light on this question is the issue which shall be addressed in the present paper.

Most contributions up to now have focussed either on the question whether one type of education - either in the form of increasing human or social capital - is a useful instrument to mitigate conflict behavior. Guttman et al. (1992) for example, examined how education in the form of influencing preferences can lead to Pareto improvement in a situation involving rent-seeking behavior. Usher (1997) examined how education can reduce the equilibrium share of bandits in an economy. In his model, he does not discriminate between different forms of education. Education leads to increased incentives for production (in the form of higher wages) as well as decreasing the criminal's propensity to engage in stealing. Grossman and Kim (2004) on the other hand, analyze in which form increasing the human capital of prospective criminals can lead to a decrease of their conflict efforts and the choice of a productive life as an honorable farmer. Still, these last two approaches share one central aspect: the individuals involved have to decide on a certain model of life: being either a productive member of society or a thief. Increasing an individual's human capital therefore leads to an increased opportunity cost of conflict in the form of forgone production. Nevertheless, whether this argument holds in a situation where people do not have to choose between 
being either a producer or a predator is not clear at all. If every individual has the option to engage in both activities it might as well be argued, that increased productivity increases the incentives to steal from the more productive individuals inducing them to increase instead of decreasing their conflict effort. The net effect is not clear. This is the issue which shall be highlighted in the following analysis.

Building a simple stylized model of two parties which are involved in some kind of struggle over a resource which has to be produced endogenously we analyze the different forms of education and their impact on the choices for production and conflict. We find that contrary to first intuition whereas increasing the social capital of individuals leads to increased production and less conflict, increasing the human capital of the individuals not necessarily leads to less appropriative effort and decreased conflict. More specifically, the results depend on whether the more or less productive individual's human capital is increased and the productivity gap between the contestants. The analysis will proceed as follows: In Section 2 we analyze the impact of education on a society with homogenous agents. In Section 3 we generalize the analysis to a society in which individuals are heterogenous with respect to their human capital. Section 4 analyzes in which circumstances individuals would choose to invest into social capital. Section 5 concludes the analysis.

\section{A homogenous society}

\subsection{The model}

In this section we build a simple stylized model of an economy in which two individuals have to face the choice of whether to spend time on the production of a resource for consumption $R$ or on appropriation of the self-same resource. Each individual $i \in\{1,2\}$ may either spend effort on production $e_{i}$ or appropriation $a_{i}$. In their choice they are constrained by the fact, that they only have a certain amount of time or energy available to spend on either activity. We will normalize the value of that non-contestable input resource to one: $e_{i}+a_{i}=1$. The value of the produced resource is given by $R=\phi\left(e_{1}+e_{2}\right)$ where $\phi>0$ is a parameter reflecting the productivity of the individuals in the economy. Still, each individual has to spend effort to gain a share of the resource. The more effort she spends on this conflict for the distribution of the resource the higher that share will be. The more effort her opponent spends the smaller that share will be. We will assume that the share each individual is able to secure for herself is given by $\pi_{i}=\frac{a_{i}}{a_{i}+a_{j}}$ with $i, j \in\{1,2\}, i \neq j$ and $\pi_{i}(0,0)=\frac{1}{2}$. Whereas each individual gains utility through the consumption of the share of the resource she managed to secure for herself, she is still subject to the education and norms that shaped her preferences during her upbringing. This is reflected by the fact that the norms regulating conflict behavior lead to disutility the moment the individual engages in conflict. As we assume a homogenous society the strength of this internalized norm is reflected by the morality parameter $\mu>0$ which is the same for both individuals. The higher $\mu$ the more moral the individuals are. Furthermore, each individual gains some utility from being part of the social community, which equals $f(\mu)$, with $f$ being a continuous and twice differentiable 
function in $\mu$, with $\frac{\partial f}{\partial \mu}>0$ and $\frac{\partial^{2} f}{\partial \mu^{2}} \leq 0$. One can imagine this to be some utility gain due to increased trust in a society, a shared sense of community or other extra benefits from belonging to a certain group. This benefit is higher, the stronger the civic norms impact on the conflict behavior. ${ }^{1}$ Each individual's utility function therefore takes the following form:

$$
u_{i}=f(\mu)+\pi_{i} R-\mu a_{i} .
$$

The individuals' optimization problem is

$$
\begin{array}{cl}
\max _{a_{i}, e_{i}} & u_{i} \\
\text { s.t. } & e_{i}+a_{i}=1, \\
& e_{i}, a_{i} \geq 0 .
\end{array}
$$

for $i \in\{1,2\}$. Solving the system of equations characterizing the first-order conditions one can derive the unique symmetric Nash-equilibrium in which each individual chooses the optimal decision vector $\delta_{i}^{s y m}=\left(e_{i}^{s *}, a_{i}^{s *}\right)$ where the optimal choice of variables is given by:

$$
\begin{aligned}
a_{i}^{s *} & =\frac{\phi}{2(\mu+\phi)}, \\
e_{i}^{s *} & =\frac{2 \mu+\phi}{2(\mu+\phi)} .
\end{aligned}
$$

\subsection{The effects of education on production and appropriation}

We saw, that the optimal decision of the individuals depended on the parameters which reflected their human capital - the productivity parameter $\phi$ - and their social preferences manifested in the morality parameter $\mu$. Both of these characteristics are determined to a large part by the education the individuals receive during their childhood. Abstracting from innate differences, an individual's productivity will generally increase the better the education she received. But education does not only leave its impact on the productivity of an individual. By shaping her social preferences it will exert its influence as well on the way that an individual does or does not engage in anti-social behavior. Values are transported by norms and supported by internal as well as external sanctions. Such internal sanctions, for example, include emotions like guilt or shame. External sanctions include all kinds of social costs which are imposed by the other individuals of a society upon violation of the norm. If education is successful, values and - often enough - the corresponding norms become internalized and take their impact via the costs of norm violation which regulate individual behavior. In the analysis, we will refer to the changes in the shared morality parameter $\mu$ under the heading of an individual's social capital. The term social capital has

\footnotetext{
${ }^{1}$ If we see this benefit as some kind of benefit due to increased trust, it is reasonable to assume that this trust-component will be higher the stronger conflict behavior is regulated. As this can be expected to drive down conflict in the society it lays the foundation for relatively peaceful community in which by and large your peers can be trusted.
} 
gained considerable popularity in the recent decades. Whereas its origins seem to date as far back as to authors like John Dewey and Karl Marx ${ }^{2}$ it has become especially popular with the writings of Bourdieu (1986); Coleman (1988) and Putnam (2000). ${ }^{3}$ Common to all these works is the use of the term social capital but not a common definition. Bourdieu (1986) characterizes social capital as an attribute of an individual in a social context which can be used to transform it into economic gains. The opportunity for the latter, though, depends on the nature of the social obligations and connections available to the individual. Woolcock characterizes social capital as "the norms and networks facilitating collective action for mutual benefit" (Woolcock, 1998, p.155). Putnam (2000) distinguishes between bridging and bonding social capital. Whereas the first results from loose ties between the individuals connecting large parts of the society, the latter refers to close ties within closed groups and generally serves to exclude others from the group's benefits. While recognizing, that the standard use of the term social capital is much wider and includes aspects as network effects, language and information flows due to civic engagement as well (see e.g. Putnam (2000); Coleman (1988)) we want to analyze the effect of one special aspect of social capital: the civic norms which regulate the conflict behavior of the members of a certain group. We nevertheless use the term, as we want to analyze the impact of this aspect of the form social capital: the shared norms which are reflected by the common cost $\mu{ }^{4}$ The question then arises how the different forms of education will influence the equilibrium choices, that is, conflict versus productive efforts? We will analyze each possibility in turn.

Human capital Taking a look at the optimal choices of $a_{i}^{s *}$ and $e_{i}^{s *}$ one can easily se, that if we increase the individuals' productivity the effect will be a rather surprising one. Instead of producing more and fighting less, the opposite happens.

$$
\begin{aligned}
\frac{\partial a_{i}^{s *}}{\partial \phi} & =\frac{\mu}{2(\phi+\mu)^{2}}>0 \\
& =-\frac{\partial e_{i}^{s *}}{\partial \phi}
\end{aligned}
$$

The reason why this happens is that as the value of the produced resource increases the incentives to fight for it increase as well. Even though the opportunity cost of conflict in terms of forgone production has gone up this is outweighed by the fact that the incentives for conflict in terms of the value of the prize have increased. The result is an increase in conflict and a decrease in productive effort.

\footnotetext{
${ }^{2}$ See Farr (2003) for the conceptual history of the term.

${ }^{3}$ These are just some examples of the most prominent contributors. Other contributions among many others include Woolcock (1998), Loury (1987), Portes (1998) and the authors in Dasgupta and Serageldin (1999).

${ }^{4}$ Even though this distinction between $\phi$ and $\mu$ might be a bit too strong when it comes to the different aspects of social capital, it nevertheless synthesizes and isolates the two relevant functional aspects of education.
} 
Social capital The other form education can take on individual behavior in our present context is via the influence on the social preferences of the society's individuals. This effect of the norms on the behavior is reflected by an anti-conflict norm and reflected by the shared morality parameter $\mu$. We will focus on the question how an increase in the strength with which these shared norms take effect will impact on the economic actions taken. The question then becomes how an increase the parameter $\mu$ influences the efforts of the individuals, that is her social capital. Here, the results are less surprising. We find that as the morality in the society increases, the individuals' conflict efforts go down and their productive efforts go up which fits with the intuitive expectations:

$$
\begin{aligned}
\frac{\partial a_{i}^{s *}}{\partial \mu} & =-\frac{\phi}{2(\phi+\mu)^{2}}<0 \\
& =-\frac{\partial e_{i}^{s *}}{\partial \mu}
\end{aligned}
$$

Increasing social capital leads to more production and less aggression which benefits consumption and leads the individuals closer to the x-efficient productive efforts $e_{i}^{x}=1$. We will therefore now turn to the analysis of the more general case of heterogenous individuals.

\section{A society with heterogenous agents}

In the previous section we found that in an economy of homogenous agents increasing the individuals' productivity led to increased conflict in the economy whereas increasing the individuals' morality - the measure of their social capital - led to decreased conflict and increased production. In this section, we analyze whether our previous results carry over if we allow for heterogenous agents. This will be reflected by the fact that the individuals may differ with respect to their productivity and the impact of the other benefits which accrue to an individual's social capital. The structure of the game will remain the same as in Section 2. But now,$\phi_{i}>0$ is the individual-specific parameter reflecting the productivity of individual $i$. Therefore, the value of the produced resource is given by $R=\phi_{1} e_{1}+\phi_{2} e_{2}$. Without loss of generality, we will assume that individual 1 is the more productive one: $\phi_{1} \geq \phi_{2}$. We will assume, that $\phi_{1}<\bar{\phi}=(3+2 \sqrt{2}) \phi_{2} \cdot{ }^{5}$ Second, we allow the individuals to differ with regards to the impact $n_{i}$ of extra benefit of belonging to a community of individuals that share the same moral norms. Each individual's utility function then takes the following form:

$$
u_{i}=n_{i} f(\mu)+\pi_{i} R-\mu a_{i}
$$

which then is maximized subject to the time resource constraint. Again one can compute the Nash-equilibrium from the first order conditions characterizing the optimum. This gives

\footnotetext{
${ }^{5}$ This condition is enough to guarantee an interior solution. Theoretically, it is possible that the productivity gap between the individuals is so large that the less productive individual specializes in predation and refrains from production. By making this simple assumption this case is ruled out.
} 
us each individual's optimal decision vector ${ }^{6} \delta_{i}^{*}=\left(e_{i}^{*}, a_{i}^{*}\right)$ with

$$
\begin{aligned}
e_{i}^{*} & =1-a_{i}^{*}, \\
a_{i}^{*} & =\frac{\left(\phi_{i}+\phi_{j}\right)}{2\left(\phi_{i}+\mu+\sqrt{\left(\phi_{i}+\mu\right)\left(\phi_{j}+\mu\right)}\right)},
\end{aligned}
$$

From this we can see that in a society in which the individuals share the same homogenous anti-conflict norms but differ with respect to their productivity the individual with the higher productivity will spend less effort on appropriation than the other. This confirms our first intuition that less productive individuals allocate a smaller proportion of their time on production. At the same time, we can see, that whether the individuals devote more time on production than on conflict will depend on the strength of the anti-conflict norm relative to both individuals' productivities. For example, if $\phi_{1}=10, \phi_{2}=9$ and $\mu=1$ then individual 2 devotes $a_{2} \approx 0.46$, that is about $46 \%$ of his time to appropriation. For $\phi_{1}=20$ and all else equal, this share raises to $a_{2} \approx 0.59$.

\subsection{The effect of education revisited}

Given that these optimal choices depend on the productivity and the morality of both individuals we come back to the question how the optimal choices will depend on these parameters which have been shaped by the education the individuals received during their childhood. In Section 2.2 we found that increasing the individuals' productivity via education would lead to higher conflict efforts in equilibrium whereas increasing their morality would lead to higher production. Do these results still hold in an economy in which the individuals differ with respect to their productivity? To answer this question, we will largely proceed analogously to Section 2.2.

Increasing human capital How will the choices in equilibrium change in response to changes in the productivity of one individual? Running comparative statics on the system of first-order equations characterizing the Nash equilibrium the following result can be derived:

Proposition 1 An increase in the human capital of the more productive individual, $\phi_{1}$, will have the following effects:

(i) It will induce the less productive individual to increase conflict effort $a_{2}^{*}$ and reduce her productive effort $e_{2}^{*}$ in the equilibrium.

(ii) The response of the more productive individual is ambiguous and depends on the parameter constellations. There exist parameter constellations in which $i=1$ 's appropriative equilibrium effort will increase as a response to her increased productivity.

(iii) Total equilibrium conflict effort will increase with an increase of $\phi_{1}$.

\footnotetext{
${ }^{6}$ The equilibrium results for the case in which the individuals differ in their morality can be obtained from the author upon request. But as we want to focus on the impact of shared norms, they are omitted in the present context.
} 
For proof, please see appendix A.1.

Remark: When thinking back to the special case of the homogenous society from Section 2.2 one can derive, that an asymmetric increase of one individual's productivity will induce this individual to increase her conflict effort, if at the point of equilibrium $\phi<2 \mu$.

Proposition 2 An increase in the human capital of the less productive individual, $\phi_{2}$, will have the following effects in the equilibrium:

(i) It will induce the more productive individual to increase her conflict effort $a_{1}^{*}$ and reduce her productive effort $e_{1}^{*}$ if $\phi_{2} \in\left((3-2 \sqrt{2}) \phi_{1}, \phi_{1}\right)$ or if $\phi_{2} \leq(3-2 \sqrt{2}) \phi_{1} \wedge \mu>\frac{\phi_{1}^{2}-6 \phi_{1} \phi_{2}+\phi_{2}^{2}}{8 \phi_{1}}$. (ii) The less productive individual might increase or decrease her appropriative effort depending on the parameter constellations. There exist parameter constellations in which $i=2$ 's effort will increase.

(iii) Total conflict effort will increase with an increase of $\phi_{2}$ if $2 \mu>\phi_{1}-\phi_{2}$.

For proof, please see appendix A.1.

What is the intuition for these results? If we take a look at the individuals' best-response functions we see that they take the following form:

$$
a_{i}^{*}\left(a_{j}\right)=\sqrt{\frac{\phi_{i} a_{j}\left(1+a_{j}\right)+\phi_{j}\left(1-a_{j}\right)}{\phi_{i}+\mu}}-a_{j} .
$$

Keeping all else constant, a change in $j$ 's productivity therefore has the following effect on $i$ 's incentives to engage in conflict:

$$
\frac{\partial a_{i}}{\partial \phi_{j}}=\frac{\partial a_{i}^{*}}{\partial \phi_{j}}+\frac{\partial a_{i}^{*}}{\partial a_{j}} \frac{\partial a_{j}}{\partial \phi_{j}}
$$

As $a_{j}<1$ the direct effect $\frac{\partial a_{i}^{*}}{\partial \phi_{j}}$ is unambiguously positive, giving an incentive to increase the individual's conflict effort. On the other hand $\frac{\partial a_{j}}{\partial \phi_{j}}$ cannot be signed in an unambiguous way. There exist parameter specifications for which it is positive and others for which it it negative. What about $\frac{\partial a_{i}}{\partial a_{j}}$ ? At the point of equilibrium it is zero which leads to the disappearance of the indirect effect. Therefore, the incentive to increase one's conflict effort as a best-response to an increase in the other's productivity is driven by the direct effect. Still, we have to consider the impact of the parameter change on the Nash equilibrium. There still is the issue of the opportunity cost in terms of forgone production. One can show that production in equilibrium, that is $R^{*}=\phi_{1} e_{1}^{*}+\phi_{2} e_{2}^{*}$, will always increase with an increase of $\phi_{1}$. Even though it certainly induces the less productive individual to decrease her productive effort, this is more than compensated by the fact, that the other individual has become more productive. This will even apply in the case that the more productive individual reduces productive effort because the higher productiveness now compensates for it. But equilibrium production $R^{*}$ might decrease in equilibrium in the case of an increase 
of $\phi_{2}$ if $\phi_{1}$ is above a certain critical threshold. If the more productive individual is induced to appropriate more (which might happen) this forgone production cannot be compensated by the productive effort of less productive individual.

The intuition of the above propositions can therefore be given as follows: In the case that the more productive individual's human capital increases, the marginal loss of $i=2$ from her forgone production is less than the marginal gain from her increased appropriation. Therefore, she will increase her effort - always. For the more productive individual the balance depends on the exact parameter constellations. There are cases in which she will reduce her appropriative effort, as the marginal gains are outweighed by the marginal increase of her opportunity costs. But this need not always be the case. Nevertheless, regardless of the parameter constellation: total conflict effort measured by the sum of both individuals' conflict efforts will increase with a human capital increase of the more productive individual.

In case that the less productive individual's human capital increases the results of the analysis are not as clear-cut as before and depends on the productivity gap between the two individuals' - in some cases relative to the strength of their anti-conflict norms. Still, the basic intuition stays the same. The bottom-line is that if the productivity gap between the two individuals is not too large, the more productive individual will respond with more aggression and less production to the increase in the less productive individual's human capital. The reason is simple: if the two individuals are similar enough in their productivity the opportunity cost in terms of forgone production is not as high as the extra-gains due to an increased share of the produced good. Accordingly, if the human capital of the less productive individual is too low, the reduced productive effort of the more productive individual could not be compensated by the now increased productivity of the less productive individual. But if the gap is not too large this effect does not take hold. An increase of $\phi_{2}$ then leads to increased appropriation of the more productive individual and increased total conflict effort. The above propositions characterize for which parameter constellations increasing one individual's human capital might lead to increased total conflict.

Re-examining one suggestion for conflict reduction, namely increasing the relevant parties' productivity and thereby increasing their opportunity cost of conflict, one can conclude that it needs to be treated with caution. There do exist opportunities to reduce conflict by increasing the less productive individual's human capital. Namely, if the productivity gap relative to the effective anti-conflict norms between both parties is sufficiently high the desired goal will be achieved. But in case that the individuals are close to each other in their productive potential, increased total conflict will be the consequence. One should, therefore, keep in mind that reduced total conflict is not a necessary consequence of such a policy. If the productivity gap between the involved parties for given anti-conflict norms is too small the opposite will occur.

The last possibility to be examined with respect to changes in human capital is an equal increase of both individuals' productivity. If we want to know how the equilibrium efforts change in response to this case we get: 
Proposition 3 Increasing the human capital of both individuals by the same amount $\phi$, will have the following effects in the equilibrium:

(i) The more productive individual will increase her conflict effort $a_{1}^{*}$ and reduce her productive effort $e_{1}^{*}$.

(ii) Total conflict effort will increase with an increase of $\phi$ if $1>a_{1}^{*}+a_{2}^{*}$.

For proof, please see appendix A.1.

The implication of these results is that if the structure of the economy and the conflict are such that there is no clear-cut division between two ideal types of life - being an honest and productive member of society on the one hand or being a parasitical and unproductive thief on the other hand - increasing human capital is not an option which guarantees that individuals engage in less conflict. Rather the opposite can happen. This result fits reasonable well with the observation of Diamond (1998) that throughout history increased productivity of societies usually went hand in hand with increased levels of conflict. When considering the alternative of increasing the less productive party's human capital to reduce the conflict in the economy, a careful analysis needs to be conducted if the characteristics of the economy the relative productivities as well as the strength of the social norms - fit the qualifications that will lead to the desired result. We will now turn to the effect of social capital.

Increasing social capital Turning to the question how an increase of the individuals' social capital - manifested in the parameter $\mu$-influences the choices in equilibrium, we get the following result:

Proposition 4 An increase of the social capital in the society will induce both parties to reduce their conflict effort and increase their production.

For proof, please see appendix A.1.

Once more, this result contains little surprises. Social capital in the form of strong civic norms leads to decreased conflict and as a consequence to increased production. Still, one caveat is in order. We gained the result by cleanly separating the effect of civic norms from issues of the other aspects of social capital which are often considered and impact on individuals' productivity. Still, we think that this is a valid procedure. The impact on productivity changes from changes in social capital can generally be analyzed in the same framework as the impact of other human capital changes. But as the benefits of social capital can be expected only to be reaped if no conflict occurs whereas its other components will have a full impact even in situations of conflict, separating the benefits of social capital from the benefits of human capital in situations of conflict seems to be justifiable. After all, certain extra-benefits of social capital - e.g. productivity changes due to network effects can be expected to vanish, the more your opponent invests in selfish rent-seeking activities as opposed to creating a common output. After all, if your partner/opponent can be expected to frequently sabotage you for his/her own personal gain these kinds of information flows, which are frequently named as one important component of social capital, can be expected to be reduced if not to vanish completely. We therefore think, that this separation is a valid way to synthesize certain key features and their effects in situations of conflict. 


\section{Investment into Social Capital}

\subsection{The Model}

While up to now we have just looked at the consequences of changes in the parameters it would be interesting to know into which form of capital the individuals would invest themselves. Investment into human capital has been studied in great detail. As in our model it shares many features with human capital investment models under taxation, we will not delve deeper into this issue at this point. Rather we want to focus on the determinants of investment into social capital. To keep the analysis tractable we will now modify the model as follows: each individual faces two periods in her life "childhood" and "adulthood". In each period she is endowed with one unit of time which may be used for her different activities. In adulthood these activities are productive effort $e_{i}$ and appropriation $a_{i}$. During her childhood she only faces the choice between time spend on building social capital $\tau_{i}$ and leisure $l_{i}$. In her childhood she cares about two things: leisure and the expected utility of her adulthood (which will not be discounted for simplicity reasons). In the first period she has to take an educational decision. ${ }^{7}$ The investment into social capital has a feature which distinguishes it from investment into human capital: the investment will only be successful if both individuals decide to do so. One can see this as a form of "spending time together" which leads to getting to know your opponent, building up trust and increasing the psychological burden hurting someone you have grown to know well and who in turn trusts you as well. ${ }^{8}$ Social bonding can only occur, if both individuals decide to spend time with each other. Networks can only be built, if both parties participate. With respect to the creation of social capital it takes two to tango. If only one individual chooses to invest, nothing will happen. As social capital manifests itself in the relation between individuals this approach seems justified. It is the production process of social capital which distinguishes it from human capital. And other than human capital it looses its benefits if you leave the circle of people with whom is has been build up. We therefore will assume the following production function of social capital:

$$
\mu\left(\tau_{1}, \tau_{2}\right)= \begin{cases}\sigma \tau_{1} \tau_{2} & \text { if } \tau_{i}>0, \quad i=1,2 \\ 0 & \text { else. }\end{cases}
$$

$\sigma$ is some parameter specifying the productivity of the social capital production. If the individual decides to invest into social capital the cost is equivalent to the leisure forgone: $\tau_{i}=1-l_{i}$. The individual's decision problem in period $\mathrm{t}=1$ can therefore be written as follows:

$$
\begin{aligned}
\max _{t_{i}} & u_{i}^{t=1}=l_{i}+u_{i}^{t=2} \\
\text { s.t. } \quad & 1=\tau_{i}+l_{i},
\end{aligned}
$$

\footnotetext{
${ }^{7}$ This approach can be seen as a shortcut for parents who make this investment decision for their children. But is also holds for any kind of situation in which individuals decide about social capital investment.

${ }^{8}$ Note, that this is the reason why we have chosen to speak of social capital and not of individual morality.
} 
where $u_{i}^{t=2}$ corresponds to the utility function specified in Section 3: $u_{i}^{t=2}=n_{i} f(\mu)+$ $\pi_{i} R-\mu a_{i}$. As we have chosen to neglect the aspect of human capital investment itself, we will assume that each individual is endowed with a natural productivity represented by the parameter $\phi_{i}$. The second period can therefore be described by the model from Section 3. Each individual knows that if she invests into social capital this will give her access to the extra benefits as well as change her personal costs of conflict. Social capital investment therefore is a means to commit to lower conflict efforts by an individual. The game is solved by backward induction.

The Second Stage: Production versus Predation In the second period the individual's utility is given by equation (3) as by then her preferences have been shaped by education. The indirect utility functions resulting from the optimal choices at $t=2$ as given in equations (6) and (7) are:

$$
\begin{aligned}
& v_{1}=n_{1} f(\mu)+\frac{\left(\phi_{1}+\phi_{2}\right) \sqrt{\left(\mu+\phi_{1}\right)\left(\mu+\phi_{2}\right)}}{2\left(\mu+\phi_{1}+\sqrt{\left(\mu+\phi_{1}\right)\left(\mu+\phi_{2}\right)}\right)}, \\
& v_{2}=n_{2} f(\mu)+\frac{\left(\phi_{1}+\phi_{2}\right) \sqrt{\left(\mu+\phi_{1}\right)\left(\mu+\phi_{2}\right)}}{2\left(\mu+\phi_{2}+\sqrt{\left(\mu+\phi_{1}\right)\left(\mu+\phi_{2}\right)}\right)} .
\end{aligned}
$$

The First Stage: Education Choices In the first period each individual maximizes her first period utility as given in equation (11) subject to the time-resource constraint $1=l_{i}+\tau_{i}$ and using the social capital generation technology specified in equation (10).

$$
\begin{aligned}
& \max _{\tau_{i}} u_{i}^{t=1}=n_{i} f(\mu)+\frac{\left(\phi_{i}+\phi_{j}\right) \sqrt{\left(\mu+\phi_{i}\right)\left(\mu+\phi_{j}\right)}}{2\left(\mu+\phi_{i}+\sqrt{\left(\mu+\phi_{i}\right)\left(\mu+\phi_{j}\right)}\right)}+l_{i} \\
& \text { s.t. } \quad 1=l_{i}+\tau_{i} .
\end{aligned}
$$

Please note the following: if $\phi_{1}>\phi_{2}$ the more productive individual's indirect utility function $v_{1}$ is increasing and strictly concave in $\mu$ even if $n_{1}=0$ whereas the less productive individual's indirect utility $v_{2}$ is only increasing and strictly concave in $\mu$ if

$$
f^{\prime}(\mu)>\frac{\left(\mu+\phi_{2}\right)\left(\phi_{1}^{2}-\phi_{2}^{2}\right)}{4 n_{2} \sqrt{\left(\mu+\phi_{1}\right)\left(\mu+\phi_{2}\right)}\left(\mu+\phi_{2}+\sqrt{\left(\mu+\phi_{1}\right)\left(\mu+\phi_{2}\right)}\right)^{2}}
$$

and

$$
f^{\prime \prime}(\mu)<\frac{\phi_{2}^{2}-\phi_{1}^{2}}{8 n_{2}\left(\left(\mu+\phi_{1}\right)\left(\mu+\phi_{2}\right)\right)^{\frac{3}{2}}}<0 .
$$

Therefore, investment into social capital can only be a Nash-equilibrium if $n_{2}>0, f^{\prime}(\mu)$ large enough and $f(\mu)$ being a strictly concave function of social capital. 
The exact form of the actual equilibrium will depend on the specific function which describes the extra-benefit of social capital. How could such an equilibrium look like? If for example, $\phi_{1}=\phi_{2}=\phi, n_{1}=n_{2}=n$ and $f(\mu)=\ln (\mu)$ one will find that in the resulting symmetric equilibrium the optimal time spent on social capital generation is $\tau^{*}=\min \{1, n\}$. That is, in this special case it is completely independent of the human capital as well as of the productivity of social capital production $\sigma$. Only the strength with which the extra benefit enters the individuals' utility functions is relevant for the investment decision. ${ }^{9}$ Nevertheless, this is a special case from which no general conclusions should be drawn. Note, that an equilibrium does not exist for every conceivable strictly concave functional specification of $f(\mu)$. E.g., if $\phi_{1}=\phi_{2}=\phi, n_{1}=n_{2}=n$ and $f(\mu)=\sqrt{\mu}$ no equilibrium exists. On the other hand for the same parameter specification but $f(\mu)=\mu^{\frac{1}{3}}$ we can find a solution. ${ }^{10}$ Concludingly, we can therefore say that the investment into social capital is very sensitive to the extra benefits provided by it.

\subsection{Empirical Evidence}

Summarizing the above results we can conclude that social capital investment is only in the interests of all the individuals involved if there are some extra-benefits that enter the individuals' utility calculus. The conflict-reducing effect alone will never be enough to induce the parties to invest into social capital. The more productive party has a direct interest to commit to lower conflict levels but the less productive party not. This party must be compensated. Is there evidence for the existence of these kind of benefits that are independent of actual productivity? There is evidence that this is actually the case. For the current purpose we will narrow our analysis to evidence from two categories: increased life-satisfaction and life-expectancy from social networks.

Life-Satisfaction and Happiness There exists an extensive literature that examines the effects from social capital or social contacts on well-being and happiness. Helliwell (2005), for example, finds that subjective well-being is a direct consequence of frequent contacts with family, friends and neighbors - exactly those people with whom people share social capital. He also finds that trust is seen as a consequence and a facilitator of frequently used networks, to which life satisfaction appears to be related to. Argyle (1999) states in his extensive summary that social relationships are a major source of well-being and social support also benefits mental and physical health. Religion and especially church attendance has a positive effect, especially for the elderly. This is mainly due to the close support of church communities, the relation experienced with god and optimism. This already relates

\footnotetext{
${ }^{9}$ One might question whether the extra-benefit $f(\mu)$ is really necessary for the solution to the problem. Another solution might just lie in the possibility that the more productive individual compensates the less productive for its "inconvenience" that the common behavioral norms pose. Nevertheless, one can show that in the typical contract theoretical setup in which one individual receives the other's utility, compensates her with a fixed payment for the right behavior and then chooses the socially optimal amount of social capital, welfare in $t=2$ will be independent of $\mu$ as long as the $n_{i}$ are zero. In this case, no incentives to invest in social capital exist. The mere conflict-reducing effect alone is not enough to warrant this investment.

${ }^{10}$ The solution for this functional specification then is $\tau_{i}^{*}=\min \left\{\frac{n^{3} \sigma}{27}, 1\right\}$ for $i=1,2$.
} 
to the next strand of literature which examines the impact of religion on well-being.

Religious organizations are among the first examples that come to mind when thinking about institutions that generate norms - that is a common morality. Religion often enough consists of a package of norms (moral as well as social) coupled with considerable benefits (access to public-goods, social networks, emotional support in events of stress, etc). Ellison (1991) examines the effects of religious involvement on subjective well-being. He finds a positive, direct and substantial influence of religious certainty (which is part of the package that religious involvement comes in) on life-satisfaction and personal happiness and fewer negative psychosocial consequences of traumatic events. These positive effects between existential certainty and cognitive assessments of well-being turn out to be particularly strong for individuals with low levels of formal education. This fits remarkably well with the insights from our model, namely, that the productively disadvantaged have to be specially compensated. While Ellison's survey is based in the US, Greene and Yoon (2004) find similar results for Europe as well. They examine the impact of religiosity on life-satisfaction in Europe. Their results conclude that effective religious commitment has a significant positive effect on life-satisfaction in Europe.

Life-expectancy Being alive is the ultimate precondition for experiencing any kind of utility. Interestingly enough, there exist many studies that this extra-benefit of social capital which has been alluded to above could be much more substantial than "just" increasing happiness and life-satisfaction, namely, increasing the life-span of an individual. Ross and Mirowsky (2002), for example, analyze the link between social support ${ }^{11}$ and subjective lifeexpectancy, that is, the age to which a person expects to survive. They find that subjective life-expectancy increases by an average of 1.149 years for each unit increment in the emotional support scale. Informal health support can predict as much as a 3-year difference in subjective life-expectancy. Interestingly enough, subjective life-expectancy predicts subsequent mortality over and above more objective correlates (Idler and Benyamini, 1997).

Blazer (1982) found that perception of social support was one of three factors which were reliably associated with survival in the elderly. Zuckerman et al. (1984) examined psychosocial predictors of mortality in the elderly poor. They found that religiousness, happiness and the presence of living offspring were explaining variables of survival. While the first two variables reduced the risk of mortality primarily among elderly who were in poor health, the effect of living offspring was independent from health status. These results correspond with the findings in Broadhead et al. (1983). Giles et al. (2005) find similar results for the Australian population.

Is there a link between these two kinds of benefits? Many studies suggest that there actually is a link between something as "immaterial" as happiness and life-satisfaction and

\footnotetext{
${ }^{11}$ One example of the extra-benefits of social capital was access to the network of family, friends and other support. It is these people you can turn to in times of need for emotional support or actual help.
} 
something "material" as survival. Deeg and van Zonneveld (1989) assert that there actually is a connection between happiness and longevity using the Dutch Longitudinal Study among the elderly. Mete (2005) finds similar results even for a completely different culture. Analyzing the question of predictors of elderly mortality in a Taiwanese data-set he finds that life-satisfaction in the form of a life-satisfaction index is a good predictor of survival even when health-status and other socio-economic characteristics are taken into account. Furthermore, Helliwell (2004, 2005) asserts that a country's suicide rates can be explained very well with reported life-satisfaction. Furthermore, suicide rates and the life-satisfaction index are explained by the same factors with the explaining coefficients being consistent in sign as well. ${ }^{12}$ One might therefore conclude that there is some link between happiness/lifesatisfaction and survival which even holds across different cultures.

Concluding comments There exist a number of studies which analyze the connection between variables that measure in some form or other a person's social capital and the benefits associated with it. One of these proxies are the social networks individuals have access to. Another and more concrete proxy is the involvement in religion - one of the forms with which behavior-regulating norms between individuals is commonly associated. In all the mentioned studies other explaining factors such as income, health status and other possibly confounding factors were controlled for. Therefore, one conclusion is that there is evidence for extra-benefits from social capital which are independent of the material pay-offs of social capital. Are these forms of social capital actually associated with less appropriation in a society? Although there exists an extensive literature in the fields of criminology and sociology, we shall nevertheless limit ourselves to two economic papers analyzing the issue. Lipford et al. (1993) find that the variable capturing the strength of religious involvement in a society, namely church attendance, has a significant negative effect on all kinds of criminal activities encompassing violent crimes (e.g. rape, murder) as well as non-violent crimes (e.g. theft, burglary, larceny). Hull and Bold (1995), too, find for US data that as a county's fraction of church members increases the crime rate falls at a diminishing marginal rate. They conclude that churches and religion help enforce property rights. While unable to generalize these results to all forms of social capital we can conclude that certain forms of social capital are effective in reducing conflict. Second, to be successful they must be part of a package with extra-benefits especially for those individuals that loose most from forgoing conflict.

\section{Conclusion}

Addressing the question which form of education was best suited to mitigate the shadow of conflict we found that in a society in which the value of a resource is determined endogenously and in which no clear division between the career of a producer or a thief is feasible

\footnotetext{
${ }^{12}$ Consistent in this context means that the coefficients of the same explaining variables go into opposite directions for the life-satisfaction index and suicide rates.
} 
the only way to guarantee the reduction of conflict is by increasing the social capital of a society's members. Increases in the human capital of one or both individuals increased the incentive of the opponent to increase her conflict effort. It could be shown that this effect sometimes even applied to the individual whose human capital increased. It has been proposed in many conflicts that increasing the human capital of the less productive party (or both parties) would lead to a decrease in conflict efforts. This contribution showed that while increasing human capital can sometimes show the desired result, there is no guarantee for this effect to take place. It will depend crucially on the parameter constellation prevalent in the given conflict. Especially, if the gap between the conflicting parties' productivities is not too large an increase of conflict is likely to take place. Note that, even if productive efforts go down in equilibrium the total production will generally still increase. Nevertheless, if the goal is conflict reduction increasing the human capital of a society might not be the best way to achieve this goal. Given that this is the fact, it is still worthwhile to invest in human capital. But one should be aware that at the same time the incentives for conflict increase as well.

Shedding light on the role social capital could play, we showed that increasing social capital not only was suitable to reduce the conflict present in a society. In the wake of reduced conflict the positive effect was increased production. As the individuals would fight less, more time was spend on producing goods for consumption. We could therefore see, the amount of the resource which was produced increased with an increase of social capital. This certainly held in a society of homogenous as well as heterogenous individuals. Education in the form of social capital is therefore well suited to mitigate the shadow conflict throws on an economy.

While recognizing that investment into social capital is well suited to reduce conflicts a couple of issues remain. First of all, social capital can only be generated if both parties are willing to take part in its production. This implies that even though more productive individuals always have an incentive to invest in social capital due to the ensuing reduction in conflict, this will be for nought if for the less productive individuals there are no extra-benefits coming along with it. Without these extra-benefits they will not have an incentive to invest, as they are the ones benefiting relatively more from conflict. But if they do not choose to invest, no social capital will be built. If one starts to think about the other aspects of social capital which have been excluded from the current analysis, one will find, that there are many examples how these kind of benefits are coupled with strict social norms governing interpersonal behavior: Many communities with such norms regulating their members social behavior offer in return benefits like a strong sense of community, belonging and trust. Often enough they provide public goods and social services for the weaker members of their society. Examples for this include many highly religious communities where the strict regulations of their social life are compensated by benefits to the weaker subjects of their communities, such as the elderly and the needy. A host of evidence could be found that these behavioral norms regulating conflict behavior are actually coupled with considerable immaterial benefits which are independent of issues such as income, e.g. a longer estimated life-span. Further benefits of social capital which were not illuminated in this article include the above mentioned network effect which can only function in a surrounding in which personal relations are not poisoned 
by conflict between its members. Still, the current analysis left many questions in the open.

One of these is how the results carry through if more parties than just two are involved in the respective conflict. Different forms of social capital as identified by Putnam (2000), namely bridging versus bonding social capital, could lead to group formation and merely divert conflict efforts from within the group to targets outside the group. Conflicts that treat inter-group versus intra-group effects have been analyzed by Münster (2005) and Münster and Stahl (2005). Still, the question of what actually constitutes a group or why people belong to a certain group and group-formation was not an issue in these papers. Aspects such as bridging or bonding social capital could fill this explanatory gap of how groups form. Another question relates to the determinants of the trade-off between human and social capital if the individual has the choice to invest into both kinds at the same time. Still, while the current framework does not seem to offer an answer to the latter question it still shed light on one aspect comprising the question of social capital.

Last but not least, this analysis did not answer the question whether the investment into this kind of capital should be left to the relevant parties alone or whether it should be supported by the state or third-party institutions. While the investment into human capital and its assessment from a welfare-point of view has been subject to substantive research, many questions remain in the current debates treating the issue of whether public education has the obligation to provide a common basis of norms, ethical values and to support the incentives to invest in social capital. It has been argued that social capital constitutes a public good which will be under-provided if left to the individuals themselves. One of the side benefits, which might not be internalized on a larger scale is the reduced costs of outside enforcement due to less conflict in an economy. As we have shown, the individuals with insufficient incentives to invest in social capital on their own are the less productive individuals of a society. Providing the extra-benefits needed to make those individuals enter the game might be one aspect policy makers could face when trying to solve the problem. 


\section{A Appendix}

\section{A.1 Proof of Proposition 1-4}

The basic technique of proof is basically the same for all the mentioned propositions. From the optimization problem of both individuals we get the following Lagrangian for each individual:

$$
L_{i}=f(\mu)+\pi_{i}\left(\phi_{i} e_{i}+\phi_{j} e_{j}\right)-\mu_{i} a_{i}+\lambda_{1}\left(a_{1}+e_{1}-1\right), \quad i=1,2 .
$$

The first-order conditions characterizing the inner Nash-equilibrium are:

$$
\begin{aligned}
& \frac{\partial L_{1}}{\partial a_{1}}=\frac{\partial \pi_{1}}{\partial a_{1}}\left(\phi_{1} e_{1}+\phi_{2} e_{2}\right)-\mu_{1}+\lambda_{1}=0 \\
& \frac{\partial L_{1}}{\partial e_{1}}=\pi_{1} \phi_{1}+\lambda_{1}=0 \\
& \frac{\partial L_{1}}{\partial \lambda_{1}}=a_{1}+e_{1}-1=0 \\
& \frac{\partial L_{2}}{\partial a_{2}}=\frac{\partial \pi_{2}}{\partial a_{2}}\left(\phi_{1} e_{1}+\phi_{2} e_{2}\right)-\mu_{2}+\lambda_{2}=0 \\
& \frac{\partial L_{2}}{\partial e_{2}}=\pi_{2} \phi_{2}+\lambda_{2}=0 \\
& \frac{\partial L_{2}}{\partial \lambda_{2}}=a_{2}+e_{2}-1=0
\end{aligned}
$$

We then proceeded by running the comparative statics on this system of equations and using Cramer's Rule. Note that from the resource constraints it follows automatically that $\frac{\partial a_{i}}{\partial x}=-\frac{\partial e_{i}}{\partial x}$ for any parameter $x$ and $i=1,2$.

\section{A.1.1 Proof of Proposition 1}

Proof. (i) Differentiating the system of first-order conditions (18)-(23) with respect to $\phi_{1}$ and using Cramer's Rule we get:

$$
\frac{\partial a_{2}}{\partial \phi_{1}}=\frac{a_{1}^{3} \phi_{1}-a_{1} a_{2} \phi_{2}+a_{1}^{2}\left(e_{1} \phi_{1}+a_{2}\left(\phi_{1}-\phi_{2}\right)+e_{2} \phi_{2}\right)+a_{2} e_{1}\left(\phi_{1} e_{1}+\phi_{2}\right)}{\left(\phi_{1}+\phi_{2}\right)^{2}}
$$

Evaluating this expression at the point of equilibrium we get:

$$
\left.\frac{\partial a_{2}}{\partial \phi_{1}}\right|_{a_{1}=a_{1}^{*}, a_{2}=a_{2}^{*}}=\frac{\phi_{1}-\phi_{2}+2\left(\mu+\sqrt{\left(\mu+\phi_{1}\right)\left(\mu+\phi_{2}\right)}\right)}{4\left(\mu+\phi_{1}+\sqrt{\left(\mu+\phi_{1}\right)\left(\mu+\phi_{2}\right)}\right)\left(\mu+\phi_{2}+\sqrt{\left(\mu+\phi_{1}\right)\left(\mu+\phi_{2}\right)}\right)} .
$$

As $\phi_{1}>\phi_{2}$ this expression is always positive. 
(ii) Using the same approach we get:

$$
\frac{\partial a_{1}}{\partial \phi_{1}}=\frac{a_{1}\left(e_{1}\left(\phi_{1} e_{1}+\phi_{2}\right)-\left(\phi_{1} a_{1} e_{1}+2 \phi_{2}^{2} a_{1}^{2}+2 \phi_{2} a_{1}\right)\right.}{\left(\phi_{1}+\phi_{2}\right)^{2}}
$$

Evaluated at the point of equilibrium this turns into:

$$
\left.\frac{\partial a_{1}}{\partial \phi_{1}}\right|_{a_{1}=a_{1}^{*}, a_{2}=a_{2}^{*}}=\frac{\left.\left(4 \mu+\phi_{1}-3 \phi_{2}\right)\right) \sqrt{\left(\mu+\phi_{1}\right)\left(\mu+\phi_{2}\right)}+\mu\left(\phi_{1}-\phi_{2}+\mu-\phi_{2}\left(\phi_{1}+\phi 2\right)\right)}{4\left(\mu+\phi_{1}+\sqrt{\left(\mu+\phi_{1}\right)\left(\mu+\phi_{2}\right)}\right)^{3}} .
$$

It is obvious that the sign of this expression will depend on the parameter constellations. One can derive that for parameter constellations in which $\phi_{2} \leq(3-2 \sqrt{2}) \phi_{1}$ this expression will be positive. Then again, even if this condition is violated the whole expression will be positive if $\mu$ exceeds some critical value. For example, if $\phi_{1}=10, \phi_{2}=9$ and $\mu=10$ we get that $\frac{\partial a_{1}}{\partial \phi_{1}} \approx 0.0036$.

(iii)

$$
\begin{aligned}
& \left.\left(\frac{\partial a_{1}}{\partial \phi_{1}}+\frac{\partial a_{2}}{\partial \phi_{1}}\right)\right|_{a_{1}=a_{1}^{*}, a_{2}=a_{2}^{*}}= \\
& \frac{\left(2 \mu+\phi_{1}-\phi_{2}\right)\left(8 \mu+4 \phi_{1}+4 \phi_{2}\right) \sqrt{\left(\mu+\phi_{1}\right)\left(\mu+\phi_{2}\right)}+8 \mu\left(\mu+\phi_{1}+\phi_{2}\right)+\phi_{1}^{2}+6 \phi_{1} \phi_{2}+\phi_{2}^{2}}{4\left(\mu+\phi_{1}+\sqrt{\left(\mu+\phi_{1}\right)\left(\mu+\phi_{2}\right)}\right)^{3}\left(\mu+\phi_{2}+\sqrt{\left(\mu+\phi_{1}\right)\left(\mu+\phi_{2}\right)}\right)} .
\end{aligned}
$$

Again, as $\phi_{1}>\phi_{2}$ this will always be positive.

\section{A.1.2 Proof of Propositions 2}

Proof. (i) Using the same approach as in A.1.1 we get:

$$
\left.\frac{\partial a_{1}}{\partial \phi_{2}}\right|_{a_{1}=a_{1}^{*}, a_{2}=a_{2}^{*}}=\frac{2 \mu+\phi_{2}-\phi_{1}+2 \sqrt{\left(\mu+\phi_{1}\right)\left(\mu+\phi_{2}\right)}}{4\left(\mu+\phi_{1}+\sqrt{\left(\mu+\phi_{1}\right)\left(\mu+\phi_{2}\right)}\right)\left(\mu+\phi_{2}+\sqrt{\left(\mu+\phi_{1}\right)\left(\mu+\phi_{2}\right)}\right)}
$$

So if $\phi_{2} \in\left((3-2 \sqrt{2}) \phi_{1}, \phi_{1}\right)$ or if $\phi_{2} \leq(3-2 \sqrt{2}) \phi_{1} \wedge \mu>\frac{\phi_{1}^{2}-6 \phi_{1} \phi_{2}+\phi_{2}^{2}}{8 \phi_{1}}$ then this expression will be positive.

(ii) Accordingly:

$$
\left.\frac{\partial a_{2}}{\partial \phi_{2}}\right|_{a_{1}=a_{1}^{*}, a_{2}=a_{2}^{*}}=\frac{\left(4 \mu+\phi_{2}-3 \phi_{1}\right) \sqrt{\left(\mu+\phi_{1}\right)\left(\mu+\phi_{2}\right)}+4 \mu^{2}-\phi_{1}^{2}-\phi_{1}\left(\phi_{2}+\mu\right)+3 \phi_{2} \mu}{4\left(\mu+\phi_{2}+\sqrt{\left(\mu+\phi_{1}\right)\left(\mu+\phi_{2}\right)}\right)^{3}} .
$$

If, for example, $\phi_{1}=9 \phi_{2}=1$ and $\mu=10$ then $\frac{\partial a_{2}}{\partial \phi_{2}} \approx 0.00686$. 
(iii)

$$
\begin{aligned}
& \left.\left(\frac{\partial a_{1}}{\partial \phi_{2}}+\frac{\partial a_{2}}{\partial \phi_{2}}\right)\right|_{a_{1}=a_{1}^{*}, a_{2}=a_{2}^{*}}= \\
& \frac{\left(2 \mu+\phi_{2}-\phi_{1}\right)\left(8 \mu+4 \phi_{1}+4 \phi_{2}\right) \sqrt{\left(\mu+\phi_{1}\right)\left(\mu+\phi_{2}\right)}+8 \mu\left(\mu+\phi_{1}+\phi_{2}\right)+\phi_{1}^{2}+6 \phi_{1} \phi_{2}+\phi_{2}^{2}}{4\left(\mu+\phi_{1}+\sqrt{\left(\mu+\phi_{1}\right)\left(\mu+\phi_{2}\right)}\right)\left(\mu+\phi_{2}+\sqrt{\left(\mu+\phi_{1}\right)\left(\mu+\phi_{2}\right)}\right)^{3}} .
\end{aligned}
$$

As one can see, if $2 \mu>\phi_{1}-\phi_{2}$ then this expression will be positive leading to an increase of total conflict efforts.

\section{A.1.3 Proof of Proposition 3}

Proof. (i) To derive the desired result, we split the productivity parameter $\phi_{i}, i=1,2$ into two components: $\phi_{i}=\phi+p_{i}, \phi>0$ and substitute this expression into the system of first order conditions for both individuals. We then run the comparative statics the same way as above. Note, that $\phi$ is the same for both individuals and is the part which will be equally increased for both. We get:

$$
\frac{\partial a_{1}}{\partial \phi}=\frac{\left(a_{1}-a_{2}\right)^{2}+2\left(a_{1}-2 a_{1}^{2}\right)}{2 \phi}
$$

Evaluating this expression at the point of equilibrium one can then show that this will be positive if $\phi_{1} \geq \phi_{2}$. This holds true by assumption.

(ii)

$$
\frac{\partial a_{1}}{\partial \phi}+\frac{\partial a_{2}}{\partial \phi}=\frac{1}{\phi}\left(a_{1}+a_{2}-\left(a_{1}+a_{2}\right)^{2}\right) .
$$

Therefore, if $1>\left(a_{1}+a_{2}\right)$ at the point of equilibrium the whole expression will be positive.

\section{A.1.4 Proof of Proposition 4}

Proof. Using the same approach as before we get:

$$
\begin{aligned}
& \left.\frac{\partial a_{1}}{\partial \mu}\right|_{a_{1}=a_{1}^{*}, a_{2}=a_{2}^{*}}=-\frac{\left(\phi_{1}+\phi_{2}\right)\left(\phi_{1}+\phi_{2}+2\left(\mu+\sqrt{\left(\mu+\phi_{1}\right)\left(\mu+\phi_{2}\right)}\right)\right)}{4\left(\mu+\phi_{1}+\sqrt{\left(\mu+\phi_{1}\right)\left(\mu+\phi_{2}\right)}\right)^{3}\left(\mu+\phi_{2}+\sqrt{\left(\mu+\phi_{1}\right)\left(\mu+\phi_{2}\right)}\right)}<0 \\
& \left.\frac{\partial a_{2}}{\partial \mu}\right|_{a_{1}=a_{1}^{*}, a_{2}=a_{2}^{*}}=-\frac{\left(\phi_{1}+\phi_{2}\right)\left(\phi_{1}+\phi_{2}+2\left(\mu+\sqrt{\left(\mu+\phi_{1}\right)\left(\mu+\phi_{2}\right)}\right)\right)}{4\left(\mu+\phi_{1}+\sqrt{\left(\mu+\phi_{1}\right)\left(\mu+\phi_{2}\right)}\right)\left(\mu+\phi_{2}+\sqrt{\left(\mu+\phi_{1}\right)\left(\mu+\phi_{2}\right)}\right)^{3}}<0
\end{aligned}
$$




\section{References}

Argyle, M.: 1999, Causes and correlates of happiness, in D. D. Kahneman, E. Diener and N. Schwarz (eds), Well-Being: The Foundations of Hedonic Psychology, Russel Sage Foundation, New York, pp. 353-373.

Baye, M. R., Kovenock, D. and de Vries, C.: 1994, The solution to the Tullock rent-seeking game when $r>2$ : Mixed-strategy equilibria and mean dissipation rates, Public Choice 81, 363-380.

Baye, M. R., Kovenock, D. and de Vries, C.: 1999, The incidence of overdissipation in rent-seeking contests, Public Choice 99, 439-454.

Bjornskov, C.: 2004, Social capital, political competition and corruption, Mimeo, Aarhus School of Business.

Bjornskov, C.: 2005, The multiple facets of social capital, Mimeo, Aarhus School of Business.

Blazer, D. G.: 1982, Social support and mortality in an elderly community population, American Journal of Epidemiology 115(5), 684-694.

Bourdieu, P.: 1986, Forms of capital, in J. G. Richardson (ed.), Handbook of Theory and Research for the Sociology of Education, Greenwood Press, Westport, CT, pp. 241-260.

Broadhead, W. E., Kaplan, B. H., James, S. A., Wagner, E. H., Schoenbach, V. J., Grimson, R., Heyden, S., Tiblin, G. and Gehlbach, S. H.: 1983, The epidemiologic evidence for relationship between social support and health, American Journal of Epidemiology $\mathbf{1 1 7}(5), 521-537$.

Coleman, J. S.: 1988, Social capital in the creation of human capital, American Journal of Sociology 94(Supplement: Organizations and Institutions: Sociological and Economic Approaches to the Analysis of Social Structure), S95-S120.

Dasgupta, P. and Serageldin, I.: 1999, in P. Dasgupta and I. Serageldin (eds), Social Capital: A Multifaceted Perspective, World Bank, Washington, DC.

Deeg, D. J. and van Zonneveld, R. J.: 1989, Does happiness lengthen life? the prediction of longevity in the elderly, in R. Veenhoven (ed.), How Harmful is Happiness? Consequences of Enjoying Life or not, Universitaire Pers Rotterdam.

Diamond, J.: 1998, Guns, Germs and Steal, Vintage.

Ellison, C. G.: 1991, Religious involvement and subjective well-being, Journal of Health and Social Behavior 32, 80-99.

Epstein, G. and Nitzan, S.: 2004, Strategic restraint in contests, European Economic Review 48, 201-210. 
Erlich, I.: 1975, On the relation between education and crime, Report Prepared for the Carnegie Commission of Higher Education.

Farr, J.: 2003, Social capital - a conceptual history, Political Theory 31(10), 1-28.

Giles, L. C., Glonek, G. F., Luszcz, M. A. and Andrews, G. R.: 2005, Effect on social networks on 10 year survival in very old australians, Journal of Epidemiology and Community Health 59(7), 574-579.

Greene, K. V. and Yoon, B. J.: 2004, Religiosity, economics and life satisfaction, Review o Social Economy 62(2), 245-261.

Grossman, H. I. and Kim, M.: 2004, Educational policy: Egalitarian or elitist?, Economics 6 Politics 15(3), 225-246.

Guttman, J. M., Nitzan, S. and Spiegel, U.: 1992, Rent seeking and social investment in taste change, Economics and Politics 4, 31-42.

Haveman, R. H. and Wolfe, B. L.: 1984, Schooling and economic well-being: the role of nonmarket effects, Journal of Human Resources 19(3), 377-407.

Helliwell, J.: 2004, Well-being and social capital: Does suicide pose a puzzle?, NBER Working Paper 10896.

Helliwell, J.: 2005, Well-being, social capital and public policy: What's new?, NBER Working Paper 11807.

Hillman, A. L.: 2003, Nietzschean development failures, Public Choice 119, 263-280.

Hillman, A. L. and Riley, J.: 1989, Politically contestable rents, Economics \& Politics 1, 1739.

Hillman, A. L. and Samet, D.: 1987, Dissipation of contestable rents by small numbers of contenders, Public Choice 54, 63-82.

Hull, B. B. and Bold, F.: 1995, Preaching matters: Replication and extension, Journal of Economic Behavior and Organization 27, 143-149.

Idler, E. and Benyamini, Y.: 1997, Self-rated health and mortality: A review of twenty-seven community studies, Journal of Health and Social Behavior 38, 21-37.

Leininger, W.: 1993, More efficient rent-seeking: A Münchhausen solution, Public Choice $\mathbf{7 5}, 43-62$.

Leininger, W. and Yang, C.-L.: 1994, Dynamic rent-seeking games, Games and Economic Behavior 7, 406-427.

Lipford, J., McCormick, R. E. and Tollison, R. D.: 1993, Preaching matters, Journal of Economic Behavior and Organization 21, 235-250. 
Loury, G. C.: 1987, Why should we care about group inequality?, Social Philosophy and Policy 5, 249-271.

Mete, C.: 2005, Predictors of elderly mortality: Health status, socioeconomic characteristics and social determinants of health, Health Economics 14, 135-148.

Münster, J.: 2005, Lobbying contests with endogenous policy proposals, WZB Working Paper, SPII 2005-11.

Münster, J. and Stahl, K.: 2005, War with outsiders makes peace inside, SFB TR 15 Discussion Paper No.75.

Portes, A.: 1998, Social capital: Its origins and applications in modern sociology, Annual Review of Sociology 24, 1-24.

Putnam, R. D.: 2000, Bowling Alone: The Collaps and Revival of the American Community, Simon \& Schuster, New York.

Ross, C. E. and Mirowsky, J.: 2002, Family relationship, social support and subjective life expectancy, Journal of Health and Social Behavior 43(4), 469-489.

Svendsen, G. L. H. and Svendsen, G. T.: 2004, The Creation and Destruction of Social Capital, Edward Elgar Publishing, Cheltenham, Northhampton.

Tullock, G.: 1980, Efficient rent seeking, in J. Buchanan, R. Tollison and G. Tullock (eds), Towards a Theory of the Rent-Seeking Society, Texas A\&M University Press, College Station, pp. 97-112.

Usher, D.: 1997, Education as a deterrant to crime, Canadian Journal of Economcis 30, 367384 .

Woolcock, M.: 1998, Social capital and economic development: Toward a theoretical synthesis and policy framework, Theory and Society 27(2), 151-208.

Zuckerman, D. M., Kasil, S. V. and Ostfeld, A. M.: 1984, Psychosocial predictors of mortality among the elderly poor - the role of religion, well-being and social contacts, American Journal of Epidemiology 119(3), 410-423. 